\title{
Doing our part for medical education
}

Kian Keong Poh, FRCP, FACC

W hat a good year 2019 has been for the Singapore Medical Journal (SM)). I am thankful to the editorial staff, the editors and reviewers who volunteered their time, the authors who submitted to the journal (including those whose papers were rejected) and the Singapore Medical Association (SMA) Council for moulding the $S M$ J into the journal it is today. I look forward to working together with everyone in the new year.

We are anticipating three new developments in 2020. Later this year, the $S M$ J will be launching a Continuing Medical Education (CME) series on professionalism in medical practice in collaboration with the SMA Centre for Medical Ethics and Professionalism. This is a topic that is of growing importance to the profession, and we hope that our educational efforts will aid doctors in an increasingly litigious practice environment. In addition, the journal's popular Practice Integration and Lifelong Learning (PILL) CME series will soon accept unsolicited submissions. This will be in line with the open submission policy for our other CME articles (e.g. the imaging and electrocardiography series). PILL articles are short case studies about a relevant issue in primary care, targeted at the general practitioner. Articles introduce the disease entity and contain key pointers on patient management and important updates, explaining the rationale and supporting evidence behind the practices. The series was started and continues to be headed by our specialty editor, Dr How Choon How. Finally, the SMJ will be introducing a new category for article submissions, Short Communications. These are shorter research articles that are of general interest to our readership and brief reports of research findings. More details will be revealed on the $S M$ / website in the upcoming months.

$S M$ / is close to my heart in many ways. My first ever medical journal article was an original paper on acute angle-closure glaucoma, from a project as a medical student under the mentorship of Prof Paul Chew. ${ }^{(1)}$ My first cardiology paper was a case report in the $S M$ J on blunt trauma, which I presented in the department's cardiology grand rounds as a medical officer..$^{(2)}$

Although my first two SMJ papers have been cited several times over the years, they may not affect its impact factor (IF) significantly. The IF of a journal assesses the frequency of citation within two years of article publication. It is commonly used and is an important index for authors, as academic institutions often assign credibility to authors who publish in high IF journals. ${ }^{(3,4)}$ However, it may not accurately reflect the reach and usefulness of the journal, and can be an unreliable milestone for scientific research. ${ }^{(5)}$

When I was a junior registrar, we published a case on Takotsubo cardiomyopathy. ${ }^{(6)}$ As the condition was quite new at that time, the paper was met with some cynicism: a few seniors commented that they did not believe in this entity. How could stress result in an octopus container-shaped left ventricle? Now, time has passed and the syndrome is well established. A quick search on 'Takotsubo' in PubMed revealed 4,520 articles. We have published some results ${ }^{(7)}$ and are doing our own registry on the subject, but there is still a lot to be learnt about this condition.

Last year, the $S M$ J achieved an IF of 1.141. We continue to welcome high-quality review papers, especially those on topics relevant to Singapore. Nevertheless, the journal looks beyond the citability of papers when selecting what we publish. For instance, we prioritise the publication of CME articles in each issue, with the underlying aim of enhancing the education of our doctors.

In the new year, we will carry on our goal of advancing the medical landscape while maintaining the impact of the journal. A healthy, successful and prosperous 2020 to all!

\section{REFERENCES}

1. Wong JS, Chew PT, Alsagoff Z, Poh K. Clinical course and outcome of primary acute angle-closure glaucoma in Singapore. Singapore Med J 1997; 38:16-8.

2. Poh KK, Tan HC, Chia BL, Lim YT. A case of broken heart from blunt trauma. Singapore Med J 2002; 43:423-5.

3. Poh KK. Increase in impact factor for the SMJ. Singapore Med J 2018; 59:345.

4. Poh KK. Journal publishing in our connected world. Singapore Med J 2019; 60:1-2.

5. Kiesslich T, Weineck SB, Koelblinger D. Reasons for journal impact factor changes: influence of changing source items. PLoS One 2016; 11:e0154199.

6. Poh KK, Chan MY, Chia BL. Images in cardiology: Reversible left ventricular apical ballooning after head injury. Clin Cardiol 2005; 28:30.

7. Lee $\mathrm{YP}$, Poh $\mathrm{KK}$, Lee $\mathrm{CH}$, et al. Diverse clinical spectrum of stress-induced cardiomyopathy. Int J Cardiol 2009; 133:272-5. 